ESJ Social Sciences

\title{
COVID-19: Perception of the Pandemic and the Importance of Barrier Measures by the Fruit and Vegetable Sellers of Port-Au-Prince
}

\author{
Francklin Benjamin, PhD
}

Université Quisqueya, Institut Supérieur de Formation des Enseignants

(Innoved), Port-au-Prince, Haïti

Katiana Jean, $B S$

Université Quisqueya, Faculté des Sciences Économiques et Administratives (FSEA), Port-au-Prince, Haïti

\section{Renando Antoine, $B S$}

Marc Prou, PhD

Université Quisqueya, Institut Supérieur de Formation des Enseignants

(Innoved), Port-au-Prince, Haïti

\section{Max Millien, Veterinarian}

Université Quisqueya, Laboratoire de recherche sur les zoonoses et intoxications alimentaires (LAZERIA), Port-au-Prince, Haïti

\section{Ketty Balthazard-Accou, PhD}

\section{Evens Emmanuel, PhD}

Université Quisqueya, École doctorale "Société et Environnement” (EDSE), Port-au-Prince, Haïti

Doi:10.19044/esj.2021.v17n5p165

Submitted: 03 November 2020

Accepted: 11 January 2021

Published: 28 February 2021
Copyright 2021 Author(s)

Under Creative Commons BY-NC-ND

4.0 OPEN ACCESS

Cite As:

Benjamin F., Jean K., Antoine R., Prou M., Millien M., Balthazard-Accou K. \& Emmanuel E. (2021). COVID-19: Perception of the Pandemic and the Importance of Barrier Measures by the Fruit and Vegetable Sellers of Port-Au-Prince. European Scientific Journal, ESJ, 17(5), 165. https://doi.org/10.19044/esj.2021.v17n5p165

\section{Abstract}

Covid-19 has triggered an unprecedented crisis that not only concerns health, it is also an economic, social, political and possibly humanitarian crisis. In March 2020, the WHO declared the disease to be pandemic and recommended the application of barrier measures. The research question here is to establish the level of social perception of fruit and vegetable sellers of the application of barrier measures in Haiti. This study was based on a mainly 
qualitative approach. A survey was carried out on a random sample of 50 fruit and vegetable sellers, a vulnerable social category of the metropolitan region of Port-au-Prince (RMPP). 98\% of the population studied were women; 92\% of them came from rural areas. Only $4 \%$ of the respondents declared that they practiced physical distancing versus $96 \%$ who declared that they were not able to practice it, or place one of their family members in quarantine. It appears pertinent to grasp, in future, the perception of COVID-19 by the Haitian population on the basis of a comparative approach that places several social classes and several economic activities in the contexts of their respective situations.

Keywords: Covid-19, health measures, social perception, fruit and vegetable sellers, metropolitan region of Port-au-Prince

\section{Introduction}

About a year after the appearance of the Covid-19 pandemic in the world and seven months after the official discovery of the first cases in Haiti, this disease continues to fuel concern. Indeed, all over the world, countries like Spain and France that thought they had extricated themselves from this frightening situation, are now considering the possibility of a second wave of the pandemic and are ready to implement new confinement strategies to reinforce the application of barrier measures. Several hundred deaths are being recorded every day in the USA, the country with the highest death toll due to Coronavirus, with more than 333,000 deaths at present (Johns Hopkins Universitty, 2020). Everywhere in the world, the new coronavirus is sowing disarray and worry in its wake, in varying degrees in nearly every social class. It places all of us in a position of social, psychological, economic and cultural uncertainty.

However, Yapi-Diahou (2020) declared that "Coronavirus or Covid19 has no preference for a specific environment, city or village, although cities are mentioned most. In our university and research institutions, Covid-19 has shown no preference for a particular field of education or research. It strikes and threatens indifferently, everywhere in the world. It disturbs everything, all and every one of us, wherever we are, is confined, our movements and activities restricted. But, Covid 19 is as much a source of inspiration and initiatives as a factor of daily action, and interrogations about the future, that of us all" (Yapi-Diahou, 2020). This interpretation of the reality of "COVID19 ", formulated under the angle of opportunities according to the analysis of possible positive externalities, was not obvious in March 2020, and more especially immediately following the press conference of the WHO during which only the pandemic dimension of COVID-19 was highlighted. It is enough to recall the most catastrophic forecasts of certain scientific 
institutions that predicted a hecatomb in Africa, notably south of the Sahara and in Haiti, and which constantly fuelled the news of all the media. Although the Republic of Haiti has been only slightly affected, in the opinion of all observers, by the pandemic in comparison to certain countries in Europe and Africa. Indeed, Haiti has had 9,947 confirmed cases of COVID-19 with 235 deaths as of December 28, 2020 (Johns Hopkins University, 2020). The Minister of Public Health of Haiti rightly considered it pertinent to recommend that the population should continue to apply barrier measures and be screened to detect new cases in good time. While waiting for the development of a vaccine, the recommendations currently include the application of physical distancing, mask wearing and sanitary measures (hand washing, disinfection using the appropriate products). These precautionary measures are undoubtedly necessary since, as emphasised by Peretti-Watel (2020) "the decisive challenge of health crises is the uncertainty that exists at every level, meaning the magnitude of the danger, the efficiency of the resources used to treat it, and its impacts".

Regarding these circumstances, the most disciplined people, aware of the danger facing them and benefiting from a good system of political and administrative management, clearly have a greater chance of success. In addition, it is true that: "the efficiency of crisis management policies depends on the quality of reaction of the population. Individual risk factors rely on the free behaviour of agents who may present risks for their health and that of others" (Azeng, 2020).

The present article proposes to analyse the perception of a vulnerable category of the Haitian population, more specifically fruit and vegetable sellers in the city of Port-au-Prince.

\section{Governmental recommendations, cultural elements and the perception of the risk of Covid-19}

Although different governments continue to take measures to combat Covid-19, the different strata of populations do not perceive their interests in the same way and, consequently, do not act in line with the orientations and results desired by the authorities. The application of barrier measures against Covid-19 may vary as a function of their social and economic situation. Furthermore, the perception of this disease could be influenced by the socioeconomic constraints that individuals are confronted with. Regarding the concept of perception, we choose in this work the definition given by Slovic (1987), that is "Perception of risk designates all the qualitative and quantitative judgements that individuals express when asked to evaluate a dangerous product or activity" (Slovic, 1987). In the specific case that concerns us here, we could replace dangerous activity by dangerous or risky behaviour. The hypothesis consists in postulating that, in a health crisis situation, perception 
is influenced by the socioeconomic constraints faced by individuals. This argument is also that of Azeng (2020) when she wrote: "although fully aware of the reality of the dangers to which they are exposed, economic agents may develop behavioural biases justified by arbitration between the health risks and concurrent risks with which they coexist, in particular economic risks. The management of the economic risk could therefore take precedence over that of the health risk, since priority is given to satisfying immediate needs"Azeng (2020).

In the light of this hypothesis, regarding economically highly vulnerable sectors of the population, one understands better that the level of application of measures aimed at fighting the risk depends on the type of socioeconomic constraints confronted. To better understand the situation, it is therefore important to make a choice between two types of survival: immediate survival and deferred survival. The first consists in the urgency and opportunity to give an immediate response to immediate needs. The second refers to the need to conform, regardless of all the constraints, to the legal, hygiene and health measures implemented by governments. This risk-taking capacity is identified by Attali (2009) as "active strategies" for survival, as opposed to "passive strategies" liable to lead to one's own destruction. This author observed that in a crisis situation, the poorest demonstrate a great deal of imagination to overcome it. This capacity is made possible by an "intense desire to live, great awareness of the dangers, deep knowledge of the environment, a fertile imagination, the capacity to adapt, etc." (Attali, 2009). In situations such as those of the Covid-19 pandemic, experience has shown that in general, the poorest sections of the population tend to opt for immediate survival rather than deferred survival, while remaining aware that they run the risk of losing the benefit of the latter. In no way is this behaviour suicidal, but a decision generally imposed by the magnitude of socioeconomic constraints that are, all said and done, at the origin of a conscious and deliberate choice.

Making such a decision is very close to the perception of risk studied by Barrios and Hochberg (2020) in American voters in the context of the pandemic. This perception consists, in the form of denial, in a need to colour facts or convictions to justify the risk run subsequent to behaviours that infringe official government decisions. From the sociological viewpoint this new form of risk-taking is tending to become a culture (Peretti-Watel, 2010).

Furthermore, risk-taking can also be understood as the mitigated or refractory behaviour of individuals regarding the discourse of the governing authorities. This behaviour can either result from suspicion or simply from questioning the pertinence of government decisions. In these circumstances, it may be a reflex of protestation reflecting the absence of governmental discourse or a lack of its efficiency. 
From this standpoint, it can be seen that a fine line exists between the perception of the social strata of the population regarding the present pandemic and the communication strategies used by the authorities to diffuse messages on prevention (Romeyer \& Moktefi, 2013). Therefore, it is not enough to simply communicate, it is necessary to ensure that the target audience of the message receives it at the right time and place (Lumarque, 2020).

Thus, these are the hypotheses that this study proposes to verify among a sample of fruit and vegetable sellers in an attempt to understand their social perception regarding the barrier measures imposed by the government.

\section{Methodology}

\section{Presentation of the study area}

Port-au-Prince is the capital and most populous city of Haiti. It was created by the colonial administration in 1749 to replace Cap-Français (now Cap-Haitien). Until the beginning of the 20th century, the city retained a modest size in a national multipolar territory (Anglade, 1982). Nevertheless, it exerts a great attractiveness on the rural populations and towns of other departments, which will grow stronger (Millian and Tamru, 2018). In 1950, Port-au-Prince had 143,534 inhabitants, then 494,000 in 1971, i.e. 20 years later, and in 1982, the population reached 719,517 inhabitants (Goulet, 2006). The city's population was estimated at 987,310 in 2015 with the metropolitan area estimated at a population of 2,618,894 (IHSI, 2015). The metropolitan area is defined by the IHSI as including the communes of Port-au-Prince, Delmas, Cité Soleil, Tabarre, Carrefour and Pétion-Ville (Figure 1).

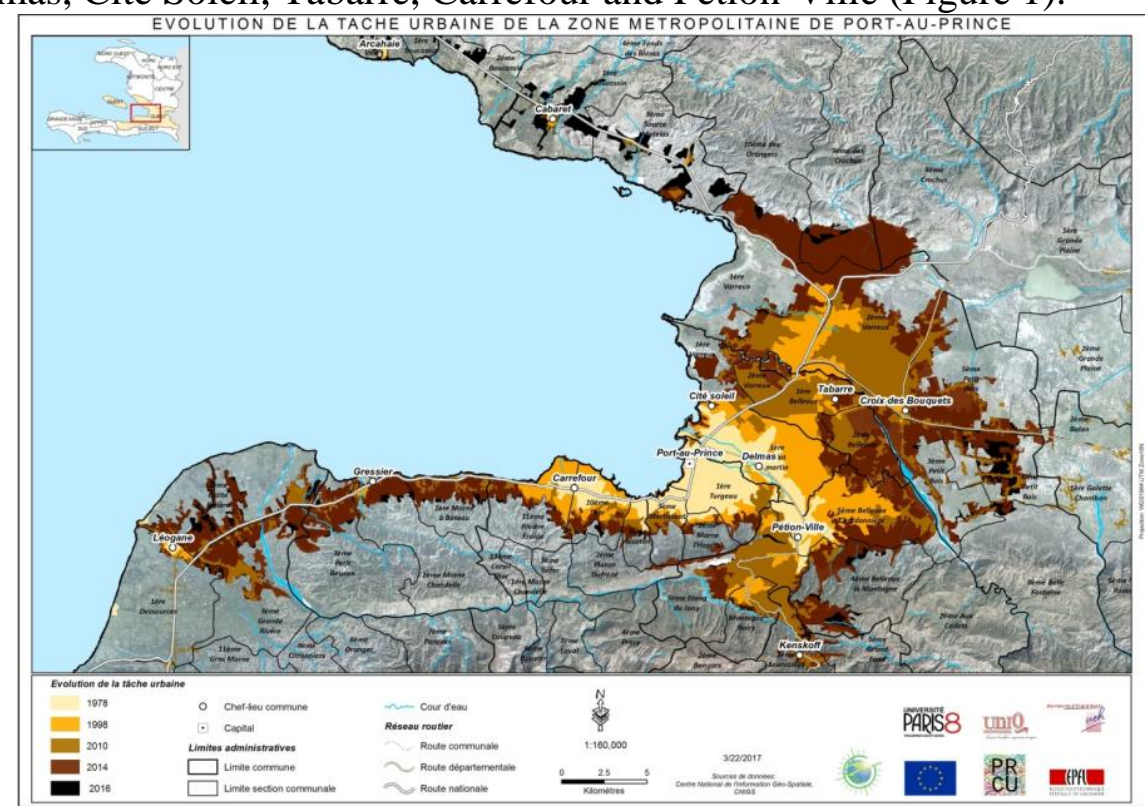

Figure 1: Evolution of the urban mark in the metropolitan area of Port-au-Prince (Tamru and Piard, 2017) 
Covering an area of around 700 ha in 1915, the agglomeration of Portau-Prince exceeded 40,000 ha in 2015 . The rate and speed of its spread is very surprising. Godard (1985) argues "the very rapid demographic growth of the agglomeration of Port-au-Prince leads to profound urban changes (unprecedented spatial extension, densification and degradation of the existing urban fabric) and an aggravation of the problems facing the city. Haitian metropolis ". According to Milan and Tamru (2018), at the turn of the new millennium, the Haitian capital spreads out in all directions, without a comprehensive development policy, and its inhabitants are mostly poor or impoverished (workers and soldiers demobilized, retired without way). The uncontrolled growth of the population and the accelerated urbanization, juxtaposed with the difficult socio-economic conditions, favor in the public spaces and in all the streets the deployment of an intense commercial activity. In fact, thousands of people daily sell and buy all types of products and services offered in fixed, semi-fixed and itinerant businesses (Bazabas, 1997) which extend on sidewalks and in streets transformed into circulation space. pedestrian (Frandes et al, 2012). In such an environment, having a position on the side of the street is preferable, for the merchants, especially when this place is close to the consumers and easily visible from the street (Sosoli, 2014).

\section{Methods}

This study was based on a mainly qualitative approach. In particular, the data collection was the subject of the application of three methods: observation, semi-structured interviews and documentary analysis.

This work consists of exploratory research that seeks to highlight the perception and the level of application of barrier measures against Covid-19 by a disadvantaged section of the population. It is a case study carried out on a sample of 50 persons chosen at random. This study gave rise to two main research questions, i.e.: i) What is the level of transmission of the new coronavirus Covid-19 in the sub-population of fruit and vegetable sellers in the metropolitan area of Port-au-Prince, which represents one of the vulnerable sections of the population from the socioeconomic standpoint? ii) What is the social perception of this category of economic agents regarding the application of the barrier measures recommended by the governmental authorities to slow down the propagation of Covid-19 in the country?

These research questions guided the construction of the data collection tool, validated beforehand by peers, the data collection as such, the processing of this data and their analysis. The analysis took into account the following factors: gender, educational and social disparities, means of access to information, knowledge of health protection measures and the medical protocol envisaged in case of contamination. 
Once the questionnaires were collected, the data entry was done using Microsoft Excel 2010 for data processing and analysis.

\section{Results and interpretation}

\section{Gender and educational and social disparities}

Out of a sample of 50 sellers, $98 \%$ of the population were women; $92 \%$ of them came from rural areas versus only $4 \%$ from urban areas, demonstrating the disparity between men and women on the job market (the percentage of unemployed women is $17.3 \%$ versus $11.5 \%$ for unemployed men). These differences originate in part from disparities existing in education which results in a low level of education for girls ( $20 \%$ of girls receive no education), the wastage rate of girls in the education system is $46 \%, 56.8 \%$ of women are illiterate (Charles et al, 2007). Hence their massive presence (55\%) in the informal sector (PNUD, 2014).

\section{Awareness, tools and access to information}

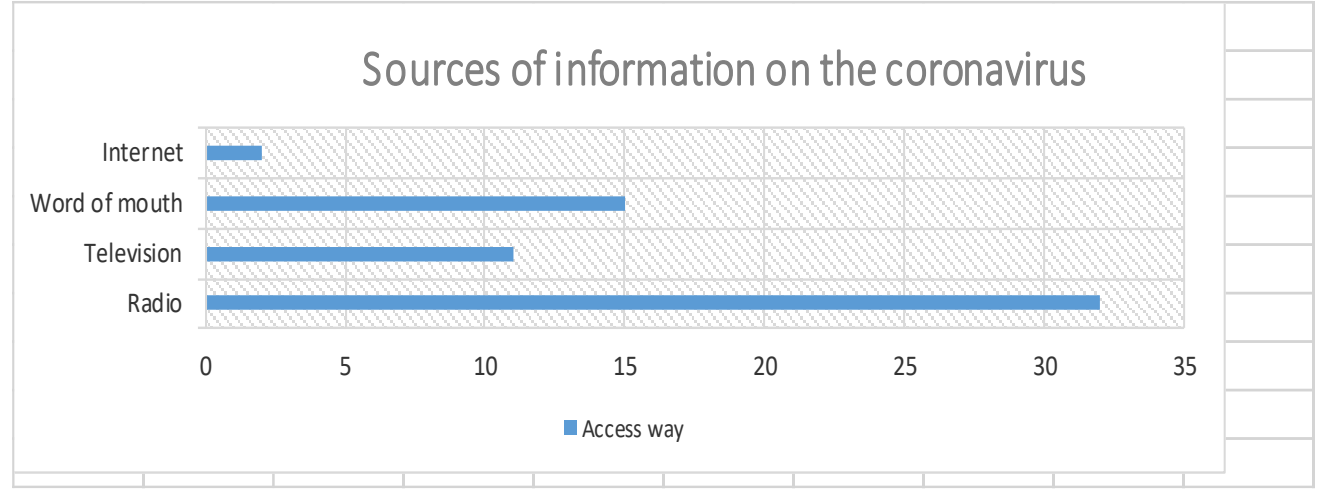

Figure 2: Sources of information on the coronavirus

As shown in figure 2, 64\% said that they had already heard about the coronavirus on the radio, $22 \%$ on television, $30 \%$ by word of mouth, versus only $4 \%$ via the internet.

These results reveal that the radio remains the privileged vector of information among the disadvantaged who have little access to modern information and technology devices. Indeed, $92 \%$ of Haitians have access to a radio set (Ayibopost, 2020). It can be seen that only 2 out of 50 of the people questioned, i.e. $4 \%$, were informed about the new coronavirus via the internet. Therefore, there is a direct link between the means of information and social category.

Overall, for the entire population surveyed, whatever the seller's area of residence or sale, they had heard about the Coronavirus at least once via the 
radio, television or during various meetings through interpersonal communication.

\section{Knowledge of health measures and constraints regarding their application}

\section{Knowledge of measures and constraints regarding their application}

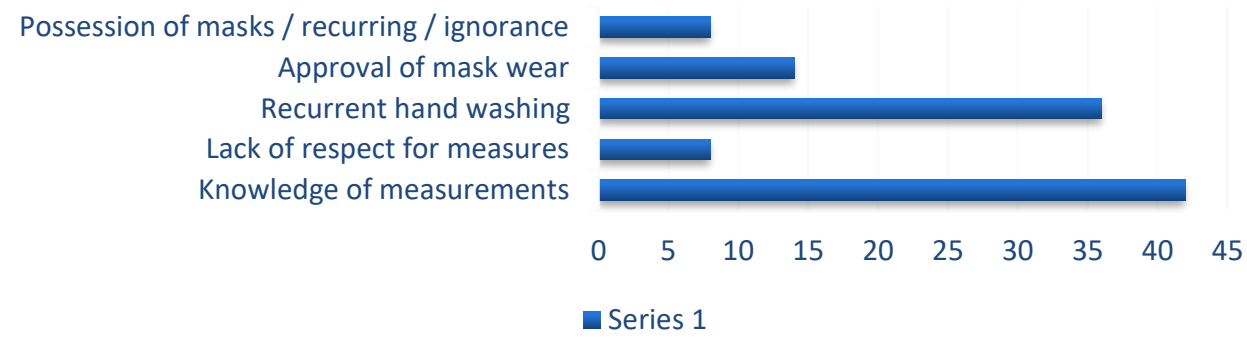

Figure 3: Knowledge of measures and constraints regarding their application

It is noteworthy that $84 \%$ of the sample said they were aware of certain preventive measures against the coronavirus (Covid19) (figure 3). This situation can be explained by the fact that the awareness campaign was not one of proximity. It remained a distant discourse disseminated by the authorities and was, by consequence, heard or believed little by a large section of the population

Moreover, $72 \%$ of the sample said they washed their hands regularly to avoid catching Covid-19, whereas only $28 \%$ asserted that wearing a mask was necessary. Despite this, only $16 \%$ of this percentage said they had a facemask, though only $10 \%$ wore one at the time of the survey. The rest said they did not take the message of the authorities seriously since the government had not made available to the sellers the infrastructures required for them to wash their hands, or the funds to purchase facemasks on a regular basis. It should be recalled that, according to the statistics, up to 2015, of the 143 districts of the metropolitan area of Port-au-Prince, 80 of them were not supplied with water (DINEPA, 2016), and that only 14\% of the population had access to water in their homes (IHE et ICF, 2018). 


\section{Practice of physical distancing and the medical protocol envisaged in case of contamination}

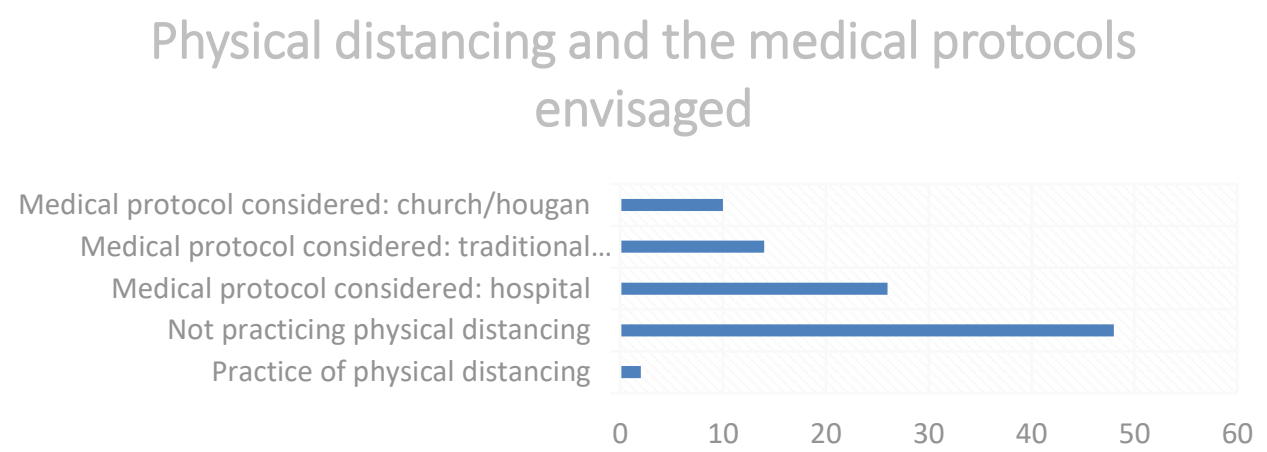

Figure 4: Physical distancing and the medical protocols envisaged

Only $4 \%$ of the respondents confirmed that they practiced physical distancing versus $96 \%$ (figure 4) who said they were unable to practice it, or place a member of their family in quarantine. On looking at the survey data, these figures are understandable given that $60 \%$ of the sellers co-habit in a house or apartment with at least 5 people. Covid-19 has highlighted the impossibility for this social category to practice physical distancing, an impossibility that highlights the social disparities that exist in most countries and which have become the underlying rationale in modern societies (Benjamin et al, 2020).

Regarding the medical protocol envisaged in the case of contamination, $52 \%$ of the persons questioned declared that in case of contamination they would go to a hospital versus $28 \%$ who preferred to resort to traditional remedies. These results do not concur with the generally accepted idea according to which the popular classes are neither used to, or have the means to, resorting to hospitals, and that they automatically choose traditional medicine as their preferred choice of treatment. This high percentage of the sample showing hospitals as the first choice can be explained by the fact that the pandemic is new and is not yet fully understood by traditional doctors. Furthermore, $10 \%$ indicated that they would go to the church, or to a hougan pour se faire soigner (to a male Voodoo priest to be cured). There is a strong presence of religion in the array of treatments, in the same way as scientific practices.

\section{Discussion}

The health measures imposed by the Haitian government are appreciated and perceived as a function of the socioeconomic conditions of the fruit and vegetable sellers. Although the population of the fruit and vegetable sellers of the metropolitan area of Port-au-Prince appeared to be 
informed of the sanitary measures recommended by the authorities, they were not fully understood by those surveyed. This was because of the material constraints facing this category of sellers (Azeng, 2020), the survival strategies adopted (Attali, 2009) and the lack of trust generally accorded in this population to the discourse communicated to it by the authorities.

There is a strong likelihood that this category of the population is not the only one concerned since other social categories are just as, or even more, vulnerable. The precarity of the living conditions of low-income earners is manifested by a kind of abandon, a divorce between the citizens and a state incapable of being treated as credible. The people feel that they have been left to fend for themselves. Indeed, $90 \%$ of the sellers stated that their daily activities (selling fruit and vegetables) are their only means of subsisting, placing them in near-poverty conditions. These measures are not considered as protective (only $2 \%$ of the respondents perceived the decisions of the Haitian government as measures taken to protect Haitian citizens), but as routine and rather empty measures having no impact on their real lives. Therefore, Covid-19 seems to be perceived differently depending on the living conditions and social category of individuals within the population. Once again, the pandemic has revealed the hiatus that exists between those who govern and the governed.

\section{Conclusion}

The objective of this work was to understand the perception of COVID-19 by a vulnerable category of the Haitian population. An exploratory survey of a sample of 50 fruit and vegetable sellers chosen at random was carried out and resulted in a summary analysis of governmental measures and cultural aspects, as well as of the respondents' perception of the risk of COVID-19. The results obtained make it possible to confirm that the measures of physical distancing, facemask wearing, and hand washing, recommended by the Haitian health authorities, were observed by only a small fraction of the population surveyed. Admittedly, the results of this study remain rather limited when taking into account the size of the sample and the diversity of the social conditions of the persons belonging to this category. However, they can facilitate deeper reflection by Haitian researchers on the various questions raised by the COVID-19 pandemic at the same time as they open doors on opportunities to develop multidisciplinary research programmes following the socioeconomic changes imposed by the pandemic. Taking these considerations into account, it is advisable to envisage the possibility of carrying out a far more exhaustive study with a more representative sample to permit its extrapolation to the entire population of fruit and vegetable sellers. In addition, it also appears pertinent in the future to seek to understand how the Haitian population perceives COVID-19 on the basis of a comparative 
approach carried out in the field, on several social categories and several economic activities.

Author Contributions: Conceptualization of the study - Francklin Benjamin, Marc Prou and Katiana Jean. Writing the original draft of the study - Francklin Benjamin, Marc Prou. Preparationof the research questions guided the construction of the data collection tool - Katiana Jean and Renando Antoine. Validation of the data collection tool - Evens Emmanuel, Max Millien and Ketty Balthazard-Accou. The data collection, the processing of data and their analysis - Renando Antoine, Katiana Jean, Francklin Benjamin and Marc Prou. Writing of the first draft of the paper - Francklin Benjamin, Evens Emmanuel and Max Millien. Review, editing and revised version - Evens Emmanuel, Max Millien, Francklin Benjamin, Ketty Balthzard-Accou and Marc Prou. All authors have read and agreed to the published version of the manuscript.

Acknowledgments: The authors would liketo thank the FOKAL (Fondation Connaissance et Liberté) and the AOG (Association communautaire paysanne des Originaires de Grande Plaine) for their support for their financial support.

Conflicts of Interest: The authors declare no conflict of interest. The funders had no role in the design of this study; in the collection, analyses, or interpretation of data; in the writing of the manuscript, or in the decision to publish the results.

\section{References:}

1. Attali, J. (2009). Survivre aux crises. Paris:Éditions Fayard. 72 p.

2. Ayibopost (2020). La radio reste le média préféré des Haïtiens. Ce n'est pas par hasard! https://ayibopost.com/en-2019-la-radio-reste-lemedia-prefere-des-haitiens-ce-nest-pas-hasard/

3. Azeng, F.T. (2020). Risque sanitaire et rationalité des agents économiques : Cas de la Covid-19. In S. Moungou Mbenda et V. Ondoua Biwole, Épidémiologie de l'économie et confinement de l'organisation : covid-19. Yahounde:LesPuy (Les Presses Universitaires de Yaoundé), p. 35-48.

4. Barrios., J. M., \& Hochberg, Y. (2020). Risk perception through the lens of politics in the time of the covid-19 pandemic (No. w27008). National Bureau of Economic Research.

5. Bazabas, D. (1997). Du marché de rue en Haïti: Le système urbain de Port-au-Prince à ses entreprises" d'espace-rue". Editions L'Harmattan. 
6. Benjamin, F., Millien, M., \& Emmanuel, E. (2020). Covid-19: changes in living and socioeconomic shifts in the spotlight. 〈hal-02963605〉. URL: https://hal.archives-ouvertes.fr/hal-02963605v1.

7. Charles., J. M., Abraham, J., Basque, J., Dalencour, P., Darius, V., Edmé, R., \& Henri, F. (2007). La stratégie nationale d'action pour l'éducation pour tous. Port-au-Prince: MENJS (Ministère de l'Education Nationale, de la Jeunesse et des Sports, 175p.

8. Dinepa (2016). Actualisation du plan stratégique sectoriel de la Dinepa. Rapport de Diagnostic. Port-au-Prince: Direction nationale de l'eau potable et de l'assainissement.

9. Fernandes, R.C., Voltaire, L., Neiburg, F. (2012). Les marchés du centre de Port-au-Prince. Morphologie, circuits, agents, gouvernance. Port-au-Prince: Viva Rio, 88p.

10. Godard, H. (1985). Port-au-Prince (Haïti). Les «quartiers» et les mutations récentes du tissu urbain. Les Cahiers d'Outre-Mer, 38(149), 5-24.

11. Goulet, J. (2006). L'organisation des services urbains: réseaux et stratégies dans les bidonvilles de Port-au-Prince (Doctoral dissertation, Université du Québec à Montréal).

12. IHE et ICF. (2018). Enquête Mortalité, Morbidité et Utilisation des Services (EMMUS-VI 2016-2017). Pétion-Ville:IHE (Institut Haïtien de l'Enfance), et Rockville:ICF.

13. IHSI. (2015). Population totale, de 18 ans et plus: Ménages et densités estimés en 2015. Port-au-Prince: IHSI (Institut Haïtien de Statistique et d'Informatique). 131p.

14. Johns Hopkins University. (2020). COVID-19 Dashboard by the Center for Systems Science and Engineering (CSSE) at Johns Hopkins University. https://coronavirus.jhu.edu/map.html. December $28^{\text {th, }}$ 2020.

15. Lumarque, J. (2020). Haïti et le covid-19. Des outils pour comprendre et agir. [Ouvrage collectif, sous la direction de Jacky Lumarque]. Portau-Prince:PressUniQ Les Presses de l'Université Quisqueya). 326p.

16. Milian, J., \& Tamru, B. (2018). Port-au-Prince, ville du risque? Un mythe au prisme d'une urbanisation vulnérable. Études caribéennes, (39-40).

17. Peretti-Watel, P. (2020). Sociologie du risque et crises sanitaires : un éclairage sur la pandémie du coronavirus. Propos recueillis le 27 mars 2020 par Anne Châteauneuf-Malclès pour SES-ENS. Entretien publié le 4 avril 2020 : http://ses.ens-lyon.fr/articles/sociologie-du-risque-etcrises-sanitaires-un-eclairage-sur-la-pandemie-du-coronavirus accédé le 19 avril 2020. 
18. Peretti-Watel, P. (2010). La société du risque. La Découverte, «Repères », 2010, 128 pages. ISBN : 9782707164568. URL : https://www.cairn.info/la-societe-du-risque--9782707164568.htm

19. PNUD. (2014). Rapport OMD 2013, Haïti : un nouveau regard. Portau-Prince: Programme des Nations Unies pour le développement (PNUD), République d'Haïti.

20. Romeyer, H., \& Moktefi, A. (2013). Pour une approche interdisciplinaire de la prévention. Communication langages, (2), 3347.

21. Slovic, P. (1987). Perception of Risk. Science (80). 236 (4799): 2805.

22. Sosoli, I. (2014). Managing and marketing of the products of fruit treeregion of Korca Albania. European Scientific Journal, 10(19).

23. Tamru, B. et B. Piard (dir.) (2017). Cahier cartographique du programme : Port-au-Prince entrevulnérabilité et croissance urbaine, construction d'une métropole caribéenne. Port-au-Prince: Centre National del'Information Géo-Spatiale.

24. Yapi-Diahou, A. (2020). Cahier " COVID 19 au quotidien ". 125 p. hal-02859844 